\title{
Clinical and metabolic profile and its relationship with insulin resistance among school children
}

\author{
Perfil clínico e metabólico e sua relação com resistência à insulina entre escolares
}

Jéssica Denise Vieira Leal ${ }^{1}$, Thaís Norberta Bezerra de Moura ${ }^{1}$, Vanessa Natali de Carvalho ${ }^{1}$, Ana Roberta Vilarouca da Silva ${ }^{1}$, Artemízia Francisca de Sousa ${ }^{1}$, Luisa Helena de Oliveira Lima ${ }^{1}$

Objective: to investigate the clinical and metabolic profile and its relationship with insulin resistance among school children. Methods: a cross-sectional study of 186 adolescents aged 10 to 19 years old. Clinical variables were: body mass index, waist circumference, and neck, conicity index, systolic, diastolic and mean blood pressure; and metabolic variables were: triglycerides, glucose, total cholesterol, high-density lipoprotein and low-density lipoprotein cholesterol, insulin and Homeostasis Model Assessment index. It was considered statistically significant at $\mathrm{p}<0.05$. Results: there was a prevalence of females, with $19.4 \%$ and $6.5 \%$ of overweight and obesity, respectively. The prevalence of insulin resistance was $42.5 \%$. Distribution of clinical and metabolic variables of adolescents according to quartiles of the Homeostasis Model Assessment index blood pressure, blood glucose, and insulin increased the values of the Homeostasis Model Assessment index increased. Conclusion: insulin resistance is present in adolescents, and this condition is associated with the clinical and metabolic changes.

Descriptors: Insulin Resistance; Adolescent; Health Profile.

Objetivo: investigar o perfil clínico e metabólico e sua relação com resistência à insulina entre escolares. Métodos: estudo transversal realizado com 186 adolescentes de 10 a 19 anos. Foram consideradas variáveis clínicas: índice de massa corporal, circunferência da cintura e do pescoço, índice de conicidade, pressão arterial sistólica, diastólica e média; variáveis metabólicas: triglicerídeos, glicemia, colesterol total, high-density lipoprotein e low-density lipoprotein colesterol, insulina e índice Homeostasis Model Assessment. Considerouse significância estatística p<0,05. Resultados: observou-se prevalência do sexo feminino, com 19,4\% e 6,5\% de excesso de peso e obesidade, respectivamente. A prevalência de resistência à insulina foi de $42,5 \%$. $\mathrm{Na}$ distribuição das variáveis clínicas e metabólicas dos adolescentes segundo os quartis do índice Homeostasis Model Assessment pressão arterial sistêmica, glicemia e insulina aumentaram à medida que os valores do índice Homeostasis Model Assessment elevavam. Conclusão: resistência insulínica está presente em adolescentes e esta condição associa-se às alterações clínicas e metabólicas.

Descritores: Resistência à Insulina; Adolescente; Perfil de Saúde.

${ }^{1}$ Universidade Federal do Piauí. Picos, PI, Brazil. 


\section{Introduction}

Overweight and obesity are becoming an emerging public health problem even in young people. Obesity has been considered one of the main risk factors for the early development of various comorbidities such as type II diabetes, high blood pressure, certain cancers and other health problems. In Brazil, as in other developing countries, about $30.0 \%$ of young people are classified as overweight or obese $\mathrm{e}^{(1)}$. Overweight is considered one of the major risk factors for heart disease. The process of atherosclerosis is influenced mainly by obesity, being considered the basic etiologic mechanism involved in cardiovascular disease $\mathrm{e}^{(2)}$.

The prevalence of overweight and obesity among Brazilians, highlighting the big increase in adolescence, draws attention for being one of the critical periods of life for the onset or persistence of obesity and its complications such as insulin resistance, which is one of the main metabolic disorders $^{(3)}$.

Insulin resistance is defined as a reduced response to the biological actions of insulin, abnormality due to inadequate insulin action in peripheral tissues such as adipose tissue, muscle, and liver. It is associated with excess body fat and metabolic disorders such as diabetes, dyslipidemia, hypertension, which together constitute the metabolic syndrome ${ }^{(3)}$.

Diagnosing insulin resistance is not easy due to the lack of a single method to estimate the degree of individual sensitivity to insulin. Among the different methods, there are direct methods that seek to analyze the effects of a predetermined amount of administered insulin (insulin tolerance test, suppression test of insulin and clamping) and indirect methods evaluating the effect of insulin endogenous (fasting insulin, HOMA-IR (Homeostasis Model Assessment-insulin Resistance) and the oral glucose tolerance test) $)^{(4)}$.

It is important to diagnose insulin resistance for a comparison of the metabolic and clinical profile since the World Health Organization requires assessment of insulin resistance or glucose metabolism disorder, as a change to different diagnostic criteria of the metabolic syndrome, being a diagnostic relevance assessing of the presence of metabolic changes.

In this perspective, this study aimed to investigate the clinical and metabolic profile and its relationship with insulin resistance among school children.

\section{Methods}

This is a cross-sectional study conducted in eight private elementary and high schools, in the urban area of the municipality of Picos-PI, Brazil which has grades for the age group studied (10 to 19 years old) and who agreed to participate in the study providing institutional authorization for the period from March to December 2015.

The population consisted of all adolescents aged 10 to 19 years old enrolled in private schools in the urban area of Picos., The formula for crosssectional studies with finite population was used to calculate the sample size ${ }^{(5)}: \mathrm{n}=\left(\mathrm{Z} \alpha^{2 *} \mathrm{P} * \mathrm{Q} * \mathrm{~N}\right) /\left(\mathrm{Z} \alpha^{2}\right.$ $\left.{ }^{*} \mathrm{P} * \mathrm{Q}\right)+(\mathrm{N}-1) * \mathrm{E}^{2}$. Where: $\mathrm{n}=$ sample size; $\mathrm{Z} \alpha=$ confidence coefficient; $\mathrm{N}=$ population size; $\mathrm{E}=$ absolute sampling error; $Q=$ supplementary percentage (100$\mathrm{P})$; $\mathrm{P}=$ proportion of occurrence of the phenomenon under study.

The parameters considered were the confidence level of $95.0 \%$ (1.96), the sampling error of $5.0 \%$ and a population of 2250 adolescents (1019 years old) ( $\mathrm{N}=2250)$ enrolled in schools in the urban area. The prevalence considered was the lowest expected prevalence among the variables chosen for the study $(7.0 \% \text { for hypertension })^{(6)}(\mathrm{p}=0.07)$. From the application of the formula, there was a total sample of 186 participants.

For data collection, it was used an adapted form of a study that identified the simultaneous occurrence of cardiovascular risk factors and metabolic 
syndrome in a representative sample of children and adolescents, domiciled in the city of Vitoria and investigated the socioeconomic factors associated ${ }^{(7)}$. The form contains information about identification, anthropometry, hemodynamic measurements, lipid profile, and glucose. This form was filled with the adolescent.

Adolescents who met the inclusion criteria participated in the study: age between 10-19 years old. The sample was selected by simple random sampling among all adolescents who met the eligibility criteria in schools selected for the study. The schools provided the lists of enrolled students, and a draw through the True Random Generator application was made.

Clinical variables were considered: body mass index, waist circumference, and neck, conicity index, systolic, diastolic and mean blood pressure. Metabolic variables were: triglycerides, glucose, total cholesterol, HDL (high-density lipoprotein) cholesterol and LDL-C low-density lipoprotein cholesterol, insulin and HOMA-IR.

The weight was obtained by scale type platform Filizola (Filizola, São Paulo, Brazil), placed on a smooth surface, accommodating up to $150 \mathrm{~kg}$ and accuracy of $100 \mathrm{~g}$. The subjects were barefoot and wore light clothing, positioned in the center of the scale, in a vertical plane. The height was measured in standing position, barefoot and in parallel, using a stadiometer with a resolution of $1 \mathrm{~mm}$.

For the nutritional status of the adolescents, the z-score of body mass index was used ${ }^{(8)}$. The waist circumference was measured with the individual in a vertical position at the midpoint between the lower margin of the last rib and the upper edge of the iliac crest in the horizontal plane, with graduated tape measure in millimeters.

The calculation of the conicity index ${ }^{(9)}$ was performed according to the following equation:

$$
\text { Conicity index }=\underset{0,109 \sqrt{\text { body weight }(\mathrm{kg}) / \text { height }(\mathrm{m})}}{\quad \text { Waist circumference }(\mathrm{m})}
$$

Blood pressure was checked by the classic auscultation method with a validated instrument for the research. Checking blood pressure ${ }^{(10)}$, the procedures recommended in the VI Brazilian Guidelines on Hypertension were followed. There was appropriate cuff size used to the circumference of the arms of the teenagers and a protocol for blood pressure checking was developed, considering the average of two measurements of systolic and diastolic blood pressure measured in adolescents after 5 minutes of rest. If the difference between the $1^{\text {st }}$ and $2^{\text {nd }}$ measurements of systolic blood pressure or diastolic blood pressure is greater than five $\mathrm{mmHg}$, a $3^{\text {rd }}$ measured was held and considered the average between the $2^{\text {nd }}$ and $3^{\text {rd }}$ measurements of systolic blood pressure and diastolic blood pressure ${ }^{(8)}$. For blood pressure classification, the curves to determine the percentile of the stature of children/adolescents were considered according to age and gender, according to the National High Blood Pressure Education Program of the United States and the blood pressure percentile table ${ }^{(10)}$. Mean blood pressure was determined by the following formula: mean arterial pressure $=$ systolic blood pressure + (blood pressure distólicax2) $/ 3^{(11)}$.

Laboratory tests were all performed in the laboratory contracted for this purpose and included serum total and fractions cholesterol, triglycerides, insulin and fasting glucose. Blood samples were collected via venipuncture after fasting for 12 hours. The collection was carried out in a vacuum tube containing gel without anticoagulant tab. After collecting the blood, it was centrifuged for 10 minutes at 3,000 rpm to separate the serum from the remaining components, and this was used to perform the analysis.

The total cholesterol, triglycerides, HDLcholesterol and glucose were determined using enzymatic colorimetric kit processed in Autohumalyzer A5 (Human GMBH, Kaiserslautern, Germany). Insulin was measured in ACS-180 Automated Chemiluminescence System equipment (Ciba Corning Diagnostics Corp., Medfield, MA, USA) and LDL-cholesterol levels were calculated using the 
established equation $^{(12)}$. These results were compared with reference values for childhood and adolescence ${ }^{(13)}$ of the V Brazilian Guidelines on Dyslipidemia and Prevention of Atherosclerosis.

HOMA-IR index was used to evaluate insulin resistance obtained by calculating the product of the fasting plasma insulin $(\mathrm{U} / \mathrm{mL})$ and fasting plasma glucose $(\mathrm{mmol} / \mathrm{L})$ divided by 22.5 . The cut-off used was greater or equal to 3.43 for both genders ${ }^{(14)}$.

Data were entered in Excel 2010 spreadsheets (Microsoft, Washington, USA) and analyzed using the Statistical Package for Social Sciences 20.0 International Business Machines Company, New York, USA). Continuous variables were tested for normal distribution using the Kolmogorov-Smirnov test. The differences for these variables were analyzed using the Mann-Whitney, according to the distribution. Categorical variables were analyzed by chi-square test (with correction by Fisher's exact test). For assessment of insulin resistance and its relationship with clinical and metabolic variables, the HOMA-IR index was distributed in quartiles and the differences between the values of these variables were evaluated by Kruskal-Wallis test, according to the distribution. For comparison of quartiles of HOMA-IR index in pairs, the Dunn test was used. For all analyses, a statistically significant $p$ value less than 0.05 was considered

The study complied with the formal requirements contained in the national and international standards of regulatory research involving human beings.

\section{Results}

The study included 186 adolescents of both genders. According to Table 1, there is a prevalence of female adolescents aged 15 to 19 years old. However, most of them were eutrophic, $19.4 \%$ and $6.5 \%$ were overweight and obesity respectively. The prevalence of insulin resistance was $42.5 \%$.
Table 1 - Clinical characteristics and prevalence of insulin resistance among adolescents

\begin{tabular}{lc}
\hline Variables & $\mathbf{n ( \% )}$ \\
\hline Gender & \\
Male & $71(38.2)$ \\
Female & $115(61.8)$ \\
Age (years old) & \\
$10-14$ & $79(42.5)$ \\
$15-19$ & $107(57.5)$ \\
Nutritional status & \\
Extreme slimness & $2(1.1)$ \\
Slimness & $6(3.2)$ \\
Eutrophic & $130(69.9)$ \\
Overweight & $36(19.4)$ \\
Obesity & $12(6.5)$ \\
Insulin resistance & \\
Yes & $79(42.5)$ \\
No & $107(57.5)$ \\
\hline
\end{tabular}

According to Table 2, it was observed a negative correlation between body mass index and HDL cholesterol; waist circumference and total cholesterol and HDL-cholesterol; neck circumference and total cholesterol and HDL cholesterol ( $p<0.05$ ). Systolic blood pressure and mean arterial pressure also had a negative correlation with total cholesterol and LDL-cholesterol $(\mathrm{p}<0.05)$. The body mass index, waist circumference, and neck circumference were positively correlated with insulin and HOMA-IR.

In Table 3, insulin-resistant individuals had lower median than LDL-cholesterol (93,50mg/ dL (34.80 to 171.20 ) vs. $8 \mathrm{mg} / \mathrm{dL}$ (30.00 to 158.00 ) $(\mathrm{p}=0.002))$ and higher insulin $(6,20 \mathrm{mcU} / \mathrm{dL}(1.30$ to 18.00$)$ vs. $25 \mathrm{mcU} / \mathrm{dL}(11.70$ to 89.80$)(\mathrm{p}=0.000))$ compared to adolescents who do not had insulin resistance. The other variables showed no statistically significant association with insulin resistance $(p>0.05)$.

In the distribution of the clinical and metabolic variables of adolescents, according to the HOMA-IR quartiles, it was observed the increase in median systolic blood pressure $(\mathrm{p}=0.023)$, glucose $(\mathrm{p}=0.009)$ increase in insulin $(\mathrm{p}<0.001)$ as the HOMAIR increased values, with the exception of LDLcholesterol ( $p=0.024)$, that decreased (Table 4). 
Table 2 - Correlation between clinical and metabolic characteristics of the adolescents surveyed

\begin{tabular}{|c|c|c|c|c|c|c|c|}
\hline Variables $^{\dagger}$ & Triglycerides & Glycemic & Total cholesterol & HDL-cholesterol & LDL-cholesterol & Insulin & HOMA-IR \\
\hline Body mass index & -0.024 & $-0.183^{*}$ & -0.032 & $-0.201 *$ & 0.015 & 0.103 & 0.069 \\
\hline Waist circumference & 0.031 & $-0.167^{*}$ & $-0.153^{*}$ & $-0.329 *$ & -0.092 & 0.097 & 0.072 \\
\hline Neck Circumference & 0.026 & -0.116 & -0.137 & $-0.264^{*}$ & -0.075 & 0.075 & 0.057 \\
\hline Conicity index & 0.126 & 0.083 & $-0.167^{*}$ & $-0.291^{*}$ & $-0149^{*}$ & 0.034 & 0.054 \\
\hline Systolic blood pressure & -0.040 & 0.013 & $-0.197^{*}$ & -0.073 & $-0.184^{*}$ & 0.062 & 0.062 \\
\hline Diastolic blood pressure & -0.015 & 0.015 & $-0.148^{*}$ & -0.100 & $-0.145^{*}$ & 0.097 & 0.099 \\
\hline Average blood pressure & -0.039 & 0.029 & $-0.194^{*}$ & -0.093 & $-0.186^{*}$ & 0.105 & 0.107 \\
\hline
\end{tabular}

Table 3 - Clinical and metabolic variables of children and adolescents, according to absence/presence of insulin resistance

\begin{tabular}{lccc}
\hline & \multicolumn{2}{c}{ Insulin resistance } & Presence \\
\cline { 2 - 4 } Variables $^{\ddagger}$ & Absence & $20.65(14.94-31.28)$ & 0.641 \\
\hline Body mass index & $20.38(12.65-33.27)$ & $70.30(53.70-92.50)$ & 0.277 \\
Waist circumference & $68.00(23.70-87.50)$ & $31.20(23.00-40.60)$ & 0.408 \\
Neck Circumference & $31.00(10.40-40.00)$ & $11.18(10.13-12.77)$ & 0.344 \\
Conicity index & $11.06(4.09-13.48)$ & $108.00(90.00-140.00)$ & 0.985 \\
Systolic blood pressure & $110.00(90.00-134.00)$ & $70.00(50.00-94.00)$ & 0.293 \\
Diastolic blood pressure & $70.00(50.00-92.00)$ & $82.00(67.33-101.00)$ & 0.421 \\
Average blood pressure & $83.33(63.33-100.66)$ & $78.00(33.00-342.90)$ & 0.088 \\
Triglycerides & $66.70(31.40-258.60)$ & $72.30(51.90-118.70)$ & 0.396 \\
Glycemia & $73.40(53.80-93.30)$ & $147.60(85.00-238.60)$ & 0.074 \\
Total cholesterol & $156.30(100.00-231.90)$ & $49.00(30.80-68.90)$ & 0.223 \\
HDL-cholesterol & $47.30(30.70-74.70)$ & $82.00(30.00-158.00)$ & $0.002^{*}$ \\
LDL-cholesterol & $93.50(34.80-171.20)$ & $25.00(11.70-89.80)$ & $0.000^{*}$ \\
Insulin & $6.20(1.30-18.00)$ & &
\end{tabular}

When compared quartiles groups two by two, there was a difference in median systolic blood pressure between the $1^{\text {st }}$ and $2^{\text {nd }}$ quartiles $(\mathrm{p}=0.017)$ and difference of glucose medians between the $4^{\text {th }}$ and $2^{\text {nd }}$ quartiles $(\mathrm{p}=0.032)$. All insulin groups differed by raising the median values as the HOMA-IR values increased $(p<0.001)$. LDL-cholesterol levels did not differ when compared two by two ( $p>0.05)$. 
Table 4 - Clinical and metabolic profile of the adolescents surveyed, according to quartiles of the HOMA-IR

\begin{tabular}{|c|c|c|c|c|c|}
\hline \multirow{2}{*}{ Variables } & \multicolumn{4}{|c|}{ Homeostasis Model Assessment-Insulin Resistance } & \multirow{2}{*}{$\mathbf{p}^{\dagger}$} \\
\hline & $\leq 1.028$ & 1.029-1.879 & $1.880-3.857$ & $\geq 3.858$ & \\
\hline Body mass index & $19.73(15.01-31.27)$ & $20.29(12.65-27.65)$ & $20.82(13.43-33.27)$ & $20.60(14.94-28.93)$ & 0.551 \\
\hline Waist circumference & $67.20(23.70-85.70)$ & $69.50(26.80-87.50)$ & $69.70(26.00-92.50)$ & $71.12(53.70-90.50)$ & 0.637 \\
\hline Conicity Index & $11.06(4.62-12.18)$ & $11.16(4.39-12.43)$ & $11.06(4.09-13.48)$ & $11.17(10.16-12.50)$ & 0.547 \\
\hline Neck Circumference & $31.00(10.40-38.50)$ & $31.00(11.10-40.00)$ & $31.00(12.00-40.60)$ & $31.85(23.00-36.90)$ & 0.820 \\
\hline Systolic blood pressure & $104.00(90-124)$ & $112.00(90-134)$ & $110.00(90-126)$ & $107.50(92-140)$ & $0.023^{*}$ \\
\hline Diastolic blood pressure & $68.00(50-84)$ & $68.00(50-92)$ & $70.00(58-90)$ & $68.50(50-94)$ & 0.108 \\
\hline Average blood pressure & $80.66(70.00-92.66)$ & $84.66(63.33-100.66)$ & $85.33(70.00-100.66)$ & $81.83(67.33-101.00)$ & 0.073 \\
\hline Triglycerides & $65.10(31.40-119.50)$ & $68.60(35.10-258.60)$ & $78.00(35.10-253.50)$ & $76.30(33.00-342.90)$ & 0.123 \\
\hline Glycemia & $70.10(53.80-93.30)$ & $74.50(60.00-92.10)$ & $75.90(54.00-94.40)$ & $71.20(51.90-118.70)$ & $0.009 *$ \\
\hline Total cholesterol & $152.10(100.60-227.30)$ & $161.10(105.90-231.90)$ & $150.40(100-210.90)$ & $144.40(85-238.60)$ & 0.197 \\
\hline HDL-cholesterol & $47.40(33.90-65.10)$ & $46.30(30.70-74.70)$ & $48.00(31.80-68.90)$ & $50.00(30.80-66.00)$ & 0.227 \\
\hline LDL-cholesterol & $90.20(34.80-167.50)$ & $97.20(36-171.20)$ & $86.10(42-131.40)$ & $77.10(30-158)$ & $0.024^{*}$ \\
\hline Insulin & $4.5(1.3-6.4)$ & $7.7(5,7-10.9)$ & $14.0(9.1-22)$ & $31.8(19.7-89.8)$ & $0.000^{*}$ \\
\hline
\end{tabular}

\section{Discussion}

Tracing the socioeconomic profile of adolescents, it was observed that most of the respondents are female $61.8 \%$, corroborating with other research where the female was also majority $(51.8 \%)$ and in this study the major inadequacies of total cholesterol, triglycerides, excess body fat, insulin resistance and altered insulin were in the female gender $^{(2)}$. It is known that female has deposits of visceral fat associated more strongly with an adverse metabolic profile as compared to men, having higher mobilization of fatty acids from visceral fat and a greater tendency to ectopic fat accumulation ${ }^{(15)}$.

On overweight and obesity, respectively $19.4 \%$ and $6.5 \%$, there is a prevalence of this comorbidity in this population. In a temporal research evaluating the variation in twelve years in overweight and obesity prevalence in adolescents held in the south of the country shows that there is a large increase in the prevalence of overweight in students $(43.0 \%$, $\mathrm{p}=0.009$ ) going from $21.5 \%$ in 2000 to $30.7 \%$ in 2012 . In obesity, the gain rate was even greater $(93.0 \%$, $\mathrm{p}=0.01$ ), since the prevalence nearly doubled one year to the other, from $5.0 \%$ in 2000 to $9.7 \%$ in $2012^{(16)}$.

Overweight has worsened in this age although its causes are preventable. However, it is the most developed in the world. In Brazil, according to the National School of Health Research, overweight is present in $16 \%$ of adolescents between 13 and 15 years old and obesity in $7.2 \%{ }^{(17)}$.

As one of the complications of obesity, there is the insulin resistance, which in this study was $42.5 \%$, being very similar to the literature showed a significant percentage of clinical and metabolic alterations, being hyperinsulinemia the higher one $(42.3 \%)^{(3)}$. Another research has shown the different prevalence of different methods, for insulin resistance, defined by the three proposed criteria, the HOMA-IR index found $67.9 \%$ of patients; according to the proposed clinical criteria $^{(9)} 57.1 \%$ had the condition and $43.4 \%$ of subjects were classified by glucose-insulin reason 
criterion $^{(15)}$.

The results of this study indicate the existence of a strong association between HOMA-IR and low HDL-cholesterol. Since the prevalence of change in fasting insulin and the lipid fractions HDL cholesterol and LDL cholesterol are significant, because studies have shown that hyperinsulinemia is an independent risk factor for the development of cardiovascular diseases by enhancing the appearance of dyslipidemia. In this situation, there is a decreased ability of insulin to stimulate glucose utilization by muscle and the adipose tissue, causing damage to the suppression of lipolysis, a condition that increases the circulation of free fatty acids and even alters glucose transport to target tissues inhibiting the action of insulin ${ }^{(4)}$.

When we analyzed the clinical and metabolic variables, all of them obtained negative correlation with HDL cholesterol, confirming that HDLcholesterol increased levels to reduce the relative risk for cardiovascular disease, by the ability of performing the reverse transport of cholesterol and preventing the oxidation and aggregation LDL-cholesterol particles in the arterial wall, reducing the atherogenic potential of lipoproteins ${ }^{(18)}$.

In addition to the correlation with HDL cholesterol, systolic blood pressure and glucose obtained an increase of the median in the second and third quartiles, and there was increased insulin as HOMA-IR values increased, demonstrating that the components of metabolic syndrome (pressure systolic blood, blood glucose, insulin and HDL-cholesterol) are closely linked to insulin resistance. These findings are supported by studies that demonstrate the relationship between variables associated with excess weight and/or body fat, and insulin resistance and metabolic syndrome in adolescents ${ }^{(19)}$.

\section{Conclusion}

According to the results of this study, it can be concluded that insulin resistance is present in adolescents, and this condition is associated with clinical and metabolic changes. Therefore, the insulin resistance level should be monitored in all adolescents, especially overweight and/or body fat, since it seems that the higher the levels of Homeostasis Model Assessment-Insulin Resistance, the higher the frequency cardiovascular risk factors, which justifies the inclusion of insulin resistance and the metabolic syndrome component.

\section{Acknowledgments}

To the Foundation for the Piauí State Research, the research funding through FAPEPI notice/SESAPI/ MS/CNPq, Case 03/2013.

\section{Collaborations}

Leal JDV, Moura TNB, Silva ARV and Sousa AF contributed to the final approval of the version to be published and writing the article. Carvalho VN contributed to the project design and data analysis. Lima LHO contributed to the project design, data analysis, drafting and final approval of the article and relevant critical review of the intellectual content.

\section{References}

1. Burgos MS, Reuter CP, Possuelo LG, Valim ARM, Renner JDP, Tornquist L, et al. Parâmetros de obesidade como preditores de desenvolvimento precoce de fatores de risco cardiometabólicos. Ciênc Saúde Coletiva. 2015; 20(8):2381-8.

2. Staiano AE, Gupta AK, Katzmarzyk PT. Cardiometabolic risk factors and fat distribution in children and adolescentes. J Pediatr. 2014; 164(3):560-5.

3. Faria ER, Faria FR, Franceschini SCC, Peluzio MCG, Sant'Ana LFR, Novaes JF, et al. Resistência à insulina e componentes da síndrome metabólica, análise por sexo e por fase da adolescência. Arq Bras Endocrinol Metab. 2014; 58(6):610-8.

4. Romualdo MCS, Nóbrega FJ, Escrivão MAMS. Resistência à insulina em crianças e adolescentes obesos. J Pediatr. 2014; 90(6):600-7. 
5. Luiz RR, Magnanini MMF. O tamanho da amostra em investigações epidemiológicas. In: Medronho AR, Carvalho DM, Bloch KV, Luiz RR, Werneck GL, organizadores. Epidemiologia. São Paulo: Atheneu; 2011. p. 415-27.

6. Silva MAM, Rivera IR, Ferraz MRMT, Pinheiro AJT, Carvalho ACC, Alves SW, et al. Prevalência de fatores de risco cardiovascular em crianças e adolescentes da rede de ensino da cidade de Maceió. Arq Bras Cardiol. 2005; 84 (5):387-92.

7. Molina MCB, Faria CP, Montero MP, Cade NV, Mill JG. Fatores de risco cardiovascular em crianças de 7 a 10 anos de área urbana, Vitória, Espírito Santo, Brasil. Cad Saúde Pública. 2010; 26(5):909-17.

8. World Health Organization. WHO child growth standards - methods and development: length/ height-for-age, weight-for-age, weight-for-length, weight-for-height and body mass index-for-age. Geneva: WHO; 2006.

9. Carneiro IBP, Sampaio HAC, Carioca AAF, Pinto FJM, Damasceno NRT. Antigos e novos indicadores antropométricos como preditores de resistência à insulina em adolescentes. Arq Bras Endocrinol Metab. 2014; 58(8):838-43.

10. Sociedade Brasileira de Cardiologia. Sociedade Brasileira de Hipertensão, Sociedade Brasileira de Nefrologia. VI Diretrizes Brasileira de Hipertensão. Arq Bras Cardiol. 2010; 95(supl 1):1-51.

11. Villa JKD, Silva AR, Santos TSS, Ribeiro AQ, Sant'Ana LFR. Risco de síndrome metabólica em crianças: uso de um escore único. Rev Paul Pediatr. 2015; 33(2):187-93.

12. Friedewald WT, Levy RI, Fredrickson DS. Estimation of the concentration of low-density lipoprotein cholesterol in plasma without use of the preparative ultracentrifuge. Clin Chem. 1972; 18:499-502.
13. Sociedade Brasileira de Cardiologia. V Diretriz Brasileira de Dislipidemias e Prevenção da Aterosclerose. Arq Bras Cardiol. 2013; 101(supl 1):1-20.

14. García CB, García LC, Jiménez LC, González VA, Calvo RC, Alcázar VMJ, et al. The HOMA and QUICKI indexes, and insulin and C-peptide levels in healthy children. Cut off points to identify metabolic syndrome in healthy children. An Pediatr (Barc). 2007; 66:481-90.

15. Marcadenti A, Oliveira VG, Bertoni VM, Wittke E, Dourado LP, Souza RB, et al. Resistência à insulina e indicadores antropométricos em pacientes com síndrome coronariana aguda. Rev Bras Cardiol. 2013;26(4):259-66.

16. Xavier MO, Bielemann RM, Maciel FV, Neutzling MB, Gigante PD. Variação temporal no excesso de peso e obesidade em adolescentes de escola privada do Sul do Brasil. Rev Bras Ativ Fis Saúde. 2014; 19(1):74-85.

17. Ministério da Saúde (BR). Pesquisa Nacional de Saúde do Escolar (PENSE). Rio de Janeiro: IBGE; 2009.

18. Ramos AT, Carvalho DF, Gonzaga NC, Cardoso AS, Noronha JAF, Cardoso MAA. Perfil lipídico em crianças e adolescentes com excesso de peso. Rev Bras Crescimento Desenvolv Hum. 2011; 21(3):780-8.

19. Pereira PF, Serrano HMS, Carvalho GQ Lamounier JA, Peluzio MCG, Franceschini SCC, et al. Body fat location and cardiovascular disease risk factors in overweight female adolescents and eutrophic female adolescents with a high percentage of body fat. Cardiol Young. 2012(2);162-9. 